Apart from the $\kappa$ and $\lambda$ immunoglobulin light chains, the other antigens studied-namely, cathepsin $\mathrm{G}$, cathepsin B, and factor VIII related antigen-are structurally quite distinct. It seems unlikely, therefore, that our results will not be applicable, in peroxidase sequence, to other antigens.

\title{
References
}

${ }^{1}$ Lillie RD. Histopathologic technique and practical histochemistry. New York: McGraw-Hill, 1965:391.

${ }^{2}$ Polak JM, Van Noorden S. Immunocytochemistry: practical applications in pathology and biology. Bristol: Wright-PSG, 1983;26:36-8.

${ }^{3}$ Nickols CD. Simple technique to identify haemosiderin in immunoperoxidase stained sections. J Clin Pathol 1984;37:1190-1.

${ }^{4}$ Burnett D, Crocker J, Stockley RA. Cathepsin B-like cysteine proteinase activity in sputum: immunohistologic identification of cathepsin B in alveolar macrophages. Am Rev Resp Dis 1983;128:915-9.

Requests for reprints to: Dr J Crocker, Department of Histopathology, East Birmingham Hospital, Bordesley Green East, Birmingham BG5 5T.

\section{Laboratory diagnosis of peritonitis in continuous ambulatory peritoneal dialysis by lysis and centrifugation}

RC SPENCER, WK AHMAD From the Department of
Bacteriology, Royal Hallamshire Hospital, Sheffield

Continuous ambulatory peritoneal dialysis (CAPD) has become accepted as an important form of dialysis treatment for patients with end stage renal disease. ${ }^{1}$ Advantages include greater patient mobility and independence, lack of requirement for vascular access, and no fluid restriction. The most important infective complication of CAPD, as with any form of peritoneal dialysis, is undoubtedly peritonitis. ${ }^{2}$ Conventional methods of culture of peritoneal dialysate from these patients has often proved negative, despite the presence of pus cells in the peritoneal fluid and

Accepted for publication 5 March 1986 clinical evidence of infection. ${ }^{3}$ Various techniques have been investigated in an attempt to improve the rate of recovery. ${ }^{4}$ In this study we evaluated the use of a lysis-centrifugation (Isolator) blood culture system ${ }^{5}$ compared with standard laboratory techniques in the diagnosis of peritonitis in CAPD.

\section{Material and methods}

The following methods were used on 100 consecutive CAPD specimens, irrespective of the patients' clinical condition. Peritonitis was diagnosed if the following criteria were fulfilled: pain or discomfort in the abdomen, associated with a "cloudy bag" that had numbers of white blood cells in excess of 100 cell $\mathrm{mm}^{-3} .^{2}$

A count of white cells was performed on the cloudy dialysate specimens in a Fuchs-Rosenthal counting chamber. One $\mathrm{ml}$ of dialysate was mixed with $10 \mathrm{ml}$ of molten nutrient agar and poured into a sterile Petri dish. ${ }^{6}$ A $20 \mathrm{ml}$ aliquot of dialysate was centrifuged at $3000 \mathrm{rpm}$ for five minutes and $0.01 \mathrm{ml}$ of centrifuged deposit inoculated on blood agar (incubated aerobically), blood agar (incubated anaerobically), and MacConkey agar. The lysis-centrifugation system used consisted of a double stoppered tube containing $0.3 \mathrm{ml}$ of high density hydrophilic fluorinert, overlaid by $0.5 \mathrm{ml}$ of aqueous lysing solution. ${ }^{7}$ Dialysate $(10$ ml) was added aseptically, mixed, and centrifuged at $3000 \mathrm{~g}$ for 30 minutes in a $35^{\circ}$ fixed angle rotor centrifuge. After lysis and centrifugation $0.01 \mathrm{ml}$ of the concentrated sediment was inoculated on to two blood and one MacConkey agar plates. All plates were incubated for a total of 72 hours at $37^{\circ} \mathrm{C}$. Cultures were read at 24,48 , and 72 hours.

\section{Results}

Of the 100 specimens, 90 fulfilled the criteria of being obtained from a patient with peritonitis and $25(27 \%)$ of these had antibacterial activity present. Of the remaining 65 samples, the detection rates of potential pathogens were pour plates $48(74 \%)$, centrifuged deposit $51(78 \%)$, and lysis-centrifugation $56(86 \%)$. For the 25 samples with antibacterial activity present, figures were seven $(28 \%)$, six $(24 \%)$, and $13(52 \%)$, respectively. The Table shows the overall isolation

Isolation rates in 90 dialysate samples by various techniques under study

\begin{tabular}{llll}
\hline Technique & Organisms & \\
\cline { 2 - 4 } & $\begin{array}{l}\text { Gram positive } \\
(n=42)\end{array}$ & $\begin{array}{l}\text { Gram negative } \\
(n=29)\end{array}$ & $\begin{array}{l}\text { Total }(\%) \\
(n=71)\end{array}$ \\
\hline Pour plate & 38 & 17 & $55(77)$ \\
Centrifuged deposit & 36 & 21 & $57(80)$ \\
Lysis-centrifugation & 41 & 28 & $69(97)$ \\
\hline
\end{tabular}


rates of the three methods. In all, 71 bacterial isolates were obtained by all three methods of which 42 were Gram positive: coagulase negative staphylococci (25); Staphylococcus aureus (14); and Streptococcus viridans (3); 29 Gram negative: Enterobacteriaceae (18); Pseudomonas spp (9); and Campylobacter spp (2). Retrospective analysis of patient records showed that all isolates were considered to be clinically important.

\section{Discussion}

As CAPD becomes more commonplace, there is a need to greatly simplify the techniques used by the laboratories in processing peritoneal fluid from infected patients. On the basis of the present results, none of the systems evaluated was entirely satisfactory. We found the lysis-centrifugation system easy to use, however, and it achieved the highest isolation rate. Eighty six per cent of samples from patients clinically diagnosed as suffering from peritonitis but not on antibiotics and $52 \%$ of those receiving antimicrobial treatment yielded a potential bacterial pathogen. From this investigation, it therefore seems that the lysis-centrifugation system could be a useful and simple technique for the laboratory diagnosis of peritonitis in CAPD.
We acknowledge the donation of 100 Dupont Isolator tubes by BDH Diagnostic Division of Poole, Dorset.

\section{References}

${ }^{1}$ Gokal R, Ward MK. Clinical experience with CAPD in the United Kingdom. In: Atkins RC, Thompson NM, Farrell PC, eds. Peritoneal Dialysis. Edinburgh: Churchill Livingstone 1981:162-4.

${ }^{2}$ Spencer RC, Fenton PA. Complications of peritoneal dialysis. J Hosp Infect 1984;5:233-40.

${ }^{3}$ Gokal R, McHugh M, Fryer R, Ward MK, Kerr DN. Continuous ambulatory peritoneal dialysis: one year's experience in a UK dialysate unit. Br Med J 1980;281:474-7.

${ }^{4}$ Rubin SJ. Continuous ambulatory peritoneal dialysis: dialysate fluid cultures. Clinical Microbiology Newsletter 1984;6:3-5.

${ }^{5}$ Dorn GL, Land GA, Wilson GE. Improved blood culture technique based on centrifugation: clinical evaluation. J Clin Microbiol 1979;9:391-6.

${ }^{6}$ Fenton PA. Laboratory diagnosis of peritonitis in patients undergoing continuous ambulatory peritoneal dialysis. J Clin Pathol 1982;35:1181-4.

${ }^{7}$ Isenberg HD. Lysis centrifugation. Journal of Clinical Laboratory Automation 1982;2:9-11.

Requests for reprints to: Dr RC Spencer, Consultant Microbiologist, Royal Hallamshire Hospital, Glossop Road, Sheffield S10 2JF, England.

\section{Letters to the Editor}

\section{Primary mesothelioma of atrioventricular node: cause of sudden death}

A 24 year old woman died one hour after intercourse with her husband: the cause of death was a primary mesothelioma of the atrioventricular node. She had had no previous history of heart disease and had one healthy child delivered by caesarean section.

This lesion was first described by Armstrong and Monckeberg in 1911 in a $51 / 2$ year old boy. The fifteenth case was described in $1976,{ }^{1}$ and of these 15 cases, 12 were female and three were male. Eight occurred in the second and third decade, often after pregnancy. Three were over the age of 67 years, suggesting that if this lesion is not specifically looked for in the elderly it may be overlooked, though not necessarily the cause of death. In this case the only abnormality found in the heart was a thickening of the atrial wall between the coronary sinus and interventricular membranous septum, thus corresponding to the position of the atrioventricular node and conducting fibres. The section showed a lesion measuring $12 \times 3 \mathrm{~mm}$ lying beneath the endocardium. It was composed of small acini lined by epithelial cells, together with a dense fibrous tissue stroma, thus obliterating much of the neuromuscular conducting tissue. There is general agreement that the lesion is congenital, but some disagreement about its origin. It may arise from the mesothelial remnants carried in from the posterior wall of the heart as the atrioventricular node forms in the embryo, or from mesocardial cysts derived from the endodermis. Clinically, the lesion majy. present with complete heart block, Stokes Adams attacks, and sudden death. Raref has an accurate diagnosis been made before death, but complete heart block in a yours person may arouse suspicion of this lesion and for reasons unknown pace makers a not well tolerated.

EH HEMSTEP Department of Pathologits Royal Berkshire Hospita Readirt:

\section{References}

${ }^{1}$ Bharati S, Bicoff JP, Jaime L. Fridman L, M. Sudden death caused by benign tumor of the atrioventricular node. Arch Intern MQ 1976;136:224-8. 